\title{
The effect of need for achievement and normative information on rotary pursuit performance
}

\author{
JOHN F. CATALANO and DAVID F. \\ BERGER, State University of New York at \\ Cortland, Cortland, N.Y. 13045
}

Need achievement as measured by the Edwards scale was used to select high-need (HN) and lowneed (LN) individuals. HN Ss were found to be superior in rotary pursuit tracking. Both $H N$ and $L N S s$, when told their performance was above average, showed less subsequent performance decrement and reminiscence than did $S$ s who were told their performance was below average.

Rotary pursuit tracking is a relatively difficult motor task for an untrained S. It is also difficult for the Ss to judge the quality of their early performance at this task. Strickland \& Jenkins (1964) showed that the personality variable, need for approval, was predictive in pursuit rotor performance. High-need-for-approval Ss tracked better than did low-need-for-approval Ss. Positive- vs negative-approval conditions had no significant effect on the performance of either group. These approval conditions, however, were in the form of verbal information given to the $S s$ after completion of another motor task prior to the rotary pursuit trials.

It is possible that analogous positive or negative verbal information about $S$ 's performance relative to others on the pursuit rotor given during a rest period in their tracking session would affect the subsequent performance of Ss selected on the basis of another personality variable-achievement motivation. Assuming that performance on the pursuit rotor has achievement significance, fictitious positive vs negative information concerning their relative performance should provide them with a basis for judging their own performance. The information's effect may also interact with high-need achievers (HN) vs low-need achievers (LN). Information that they are performing relatively well (positive) might have a rather slight effect on HN Ss, while an indication that they are doing relatively poorly (negative information) should cause them to try even harder and thus improve. By contrast, LN Ss might ease up or coast after positive information but would not necessarily try to improve after negative information was presented. In the present experiment, Ss were not selected on the basis of need for approval, so that any possible positive or negative approval from the information presentation would have no systematic effect.

\section{APPARATUS}

A Pentagon Devices pursuit rotor (polar tracker) was used throughout the experiment. The target was a square, $3 / 4 \times 3 / 4$ in., that traveled in a 7 -in.-diarn circular path at $60 \mathrm{rpm}$. The target was a light that was tracked with a photo-sensitive stylus that had a $10 \frac{1}{4}$-in. rubber handle, bent at $90 \mathrm{deg} 2 \frac{1}{2}$ in. from the tip. The tip of the stylus was a circular nylon disk with a diameter of 5/16 in. An aperture, $2 / 16$ in. in diam, allowed light to reach a photocell that, when activated, completed a circuit that allowed the recording of time on target (TOT). The sensitivity of the photocell was adjusted so that the circuit would be completed if half of the stylus tip was on the target. When on target, the completion of the circuit activated one of two $.01 \mathrm{sec}$ digital timers.

TOT scores were recorded every $15 \mathrm{sec}$ by using alternate clocks. A Hunter Interval Cycler was used to regulate the alternation of clocks. Calibration of sensitivity and speed of target rotation was made prior to each experimental session.

The $S$ was required to stand throughout the experiment. The surface of the polar tracker was 33 in. above the floor.

The target rotated in a clockwise direction for right-handed $S s$ and in a counterclockwise direction for left-handed Ss.

\section{PROCEDURE}

The need achievement scale from the Edwards Personal Preference Schedule was administered to a group of approximately 200 introductory psychology students at SUNY, Cortland. Of these, 24 (12 males and 12 females) high-need achievement (HN) and 24 (12 males and 12 females) low-need achievement (LN) served as Ss in the experiment. HN was defined as any score at or above the 75 th percentile and LN as any score at or below the 25 th percentile. Ss did not know the nature of the scale or the basis of their selection for this particular experiment. The Marlowe Crowne Social Desirability Scale (Crowne \& Marlowe, 1960) was also given to all students. A Spearman rank-order correlation showed no significant relationship between need achievement and social desirability. It was therefore assumed that Ss were selected, as intended, primarily on the basis of their achievement motivation. This experiment commenced 6 weeks after Ss had filled out the scales.

In the experimental session, $\mathrm{S}$ was required to carry out rotary pursuit tracking for $20 \mathrm{~min}$. TOT was recorded every $15 \mathrm{sec}$ so that 80 scores were obtained from each $\mathrm{S}$, and each score was regarded as a 15-sec trial. The experimental session consisted of two phases, a training phase and a testing phase, each consisting of 40 trials. During training, $S$ tracked continuously for the 40 trials. However, in the test phase, there was a 15 -sec rest period after every four $15-\mathrm{sec}$ trials so that there was a total of 10 four-trial ( $1-\mathrm{min}$ ) tracking blocks. This procedure is similar to that previously employed by Catalano (1967) and Catalano \& Whalen (1967a, b) and allows decrement and reminiscence to occur. These performance phenomena are of primary concern in this experiment.

There was a 1-min period between the training and test phases during which $S$ was subjected to the experimental treatment. $S$ was presented with either "positive" or "negative" information concerning his performance up to that time. Positive information was presented by telling $S$, "Your performance so far has been quite a bit better than that of the average (male or female) college student." For negative information, $S$ was told, "Your performance so far has been quite a bit below that of the average (male or female) college student." This information was presented in a neutral, matter-of-fact manner, and no elaboration or discussion was allowed.

The Ss were assigned to one of the conditions independently of whether they were, in fact, above or below average.

Twelve of the $24 \mathrm{HN}$ Ss received positive information $(\mathrm{HN}+)$ and 12 received negative information ( $\mathrm{HN}-)$. These subgroups were formed by matching Ss on the basis of their TOT scores on the last two 15 -sec training trials, i.e., Trials 39 and 40. Mean TOT on these trials was $5.97 \mathrm{sec}$ for the $\mathrm{HN}+\mathrm{Ss}$ and 6.16 for the $\mathrm{HN}-\mathrm{Ss}$. A similar procedure was used to form the two LN subgroups, $\mathrm{LN}+$ and $\mathrm{LN}-$. Mean TOT scores for Training Trials 39 and 40 were

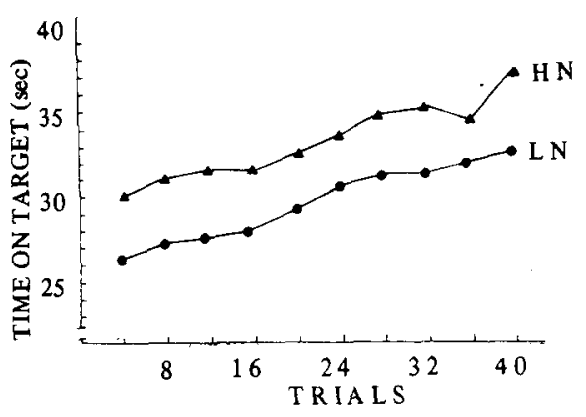

Fig. 1. Time on target summed over four-trial blocks, for test trials. 
5.39 for $\mathrm{LN}+\mathrm{Ss}$ and 4.82 for $\mathrm{LN}-\mathrm{Ss}$. Ss were matched on the basis of TOT scores only so that an uneven sex distribution resulted. The $\mathrm{HN}+$ group contained four males and eight females; $\mathrm{HN}_{-}$-, six males and six females; LNt, six males and six females; and $\mathrm{LN}-$, four males and eight females.

\section{RESULTS}

TOT was summed over every four 15 -sec trials for each $S$, and the mean for each four-trial block was determined for each group. The Friedman analysis of variance was performed on the TOT scores for each group for the final two trials of the experiment (Test Trials 39 and 40). The overall difference was not significant $(.05<p<.10)$. Therefore, the scores for the two HN groups were combined and compared to the combined scores of the two LN groups (see Fig. 1). The Mann-Whitney $U$ test showed the different in TOT attained by the end of the experiment for all $\mathrm{HN}$ Ss to be significantly higher $(z=2.21, p<.05)$.

Reminiscence scores were obtained for each $\mathrm{S}$ by computing the difference in TOT between the last $15-\mathrm{sec}$ trial prior to each rest period and the first $15-\mathrm{sec}$ trial after the rest period. Nine reminiscence scores were obtained for each $S$ for the rest periods between the 10 test blocks. Mean reminiscence for each $S$ and the grand means for each group were then determined. These were, in seconds: HN+, $-.55 ; \mathrm{HN}-,+.57 ; \mathrm{LN}+,-.10 ; \mathrm{LN}-,+.27$ (Fig. 2). A positive reminiscence value indicates improvement after rest, a negative value indicates that postrest performance was poorer than performance prior to rest. The Friedman analysis of variance revealed these differences to be significant $\left(\chi_{\mathrm{r}}{ }^{2}=8.70, \mathrm{p}<.05\right)$. The Wilcoxon test was used for individual comparison of reminiscence scores for each group. The difference between $\mathrm{HN}+$ and $\mathrm{HN}-$ was

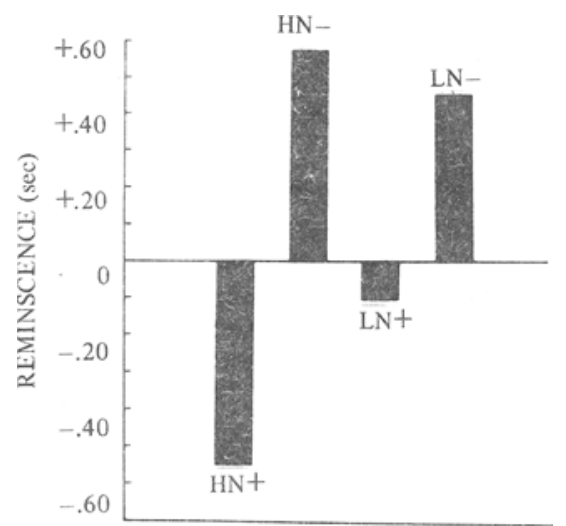

CONDITION

Fig. 2. Mean reminiscence for each condition. found to be significant $(T=8, p<.02)$, as was the difference between the $\mathrm{LN}+$ and LN-groups $(T=14, p<.01)$. Finally, the difference between all of the $S$ s receiving positive information ( $\mathrm{HN}+$ and $\mathrm{LN}+$ ) and all the Ss receiving negative information ( $\mathrm{HN}-$ and $\mathrm{LN}_{-}$) proved to be significant $(\mathrm{T}=48, \mathrm{p}<.01)$.

The dependent variable of primary interest in this experiment was considered to be reminiscence. However, reminiscence is not likely to follow rest under the conditions of this experiment unless a decrement in performance has occurred prior to the test period. Ss who do not suffer decrement, i.e., who can maintain a high level of performance, do not resume practice at a higher level than they were at prior to rest. Those Ss who are most likely to benefit from rest as those who were performing below their level of capability under the massed practice condition. Therefore, a second dependent variable is decrement. This measure was obtained by determining the difference in TOT between the second and fourth $15-\mathrm{sec}$ trials of each four-trial block. The means of the 10 test trial blocks were computed for each $S$ and then grand means determined for each condition. The decrement scores were: $\mathrm{HN}+,-.48 ; \mathrm{HN}-,-.79 ; \mathrm{LN}+,-.56 ; \mathrm{LN}-$, -.78 . As can be seen, the $\mathrm{HN}-$ and $\mathrm{LN}$ groups that showed the greatest reminiscence also showed the greatest decrement. While the Friedman test did not prove these differences to be significant, it was found that more Ss receiving positive information ( $\mathrm{HN}+$ and $\mathrm{LN}+$ ) showed less than the average amount of decrement that occurred for all $48 \mathrm{Ss}$. Fifteen of 24 positively informed Ss showed less than average decrement, while only 10 of the 24 negatively informed Ss showed less than average decrement. The differences between these proportions is significant $(\mathrm{z}=2.1, \mathrm{p}<.05)$.

No interaction occurred between type of information and reminiscence or decrement. High- and low-need achievement Ss were similarly affected by the information concerning their task performance.

\section{DISCUSSION}

The major finding of this experiment was that positive and negative information given to Ss after a period of practice at the rotary pursuit task resulted in differences between the groups in subsequent reminiscence and decrement when the task was resumed. The positive condition resulted in less decrement and, therefore, less reminiscence than that which occurred for the negative conditions. The amount of reminiscence that occurred for the negative conditions was approximately the same as that obtained under the control conditions of previous experiments that utilized the same procedure employed here (Catalano, 1967; Catalano \& Whalen, 1967a, b). Thus it appears that the difference between the conditions of the present experiment is primarily due to positive information affecting $S s$ in such a way that they were able to resist or overcome the inhibitory effects of massed practice. These Ss did not show decrement where most Ss usually do.

The phenomena of decrement and reminiscence have traditionally been explained as being due to the development and dissipation of fatigue like states such as reactive inhibition (Hull, 1943; Ammons, 1947). In the series of studies preceding this experiment, Catalano has shown that another factor that may very well play a part in both decrement and reminiscence is the change of arousal level that very likely occurs when conditions of alternating massed practice and rest are employed. In these studies, it was shown that magnitude of reminiscence could be increased, or the occurrence of decrement could be reduced, as a function of increased intensity of arousing stimulation.

In the present experiment, the effect. of the positive information was possibly motivational. If so, this increased motivation may have been responsible for improved performance by impelling Ss to sustain a high level of performance in spite of the fatigue they may have felt, or by maintaining arousal that, in turn, resulted in less decrement. Unfortunately, it is not possible to identify specifically the way in which motivation worked here.

The only difference between $\mathrm{HN}$ and $\mathrm{LN}$ Ss was in the level of performance attained. HN Ss were consistently superior to LN Ss in terms of TOT. The absence of an interaction effect between information and need for achievement is contrary to what was expected. The fact that one dependent variable (TOT) was affected only by need for achievement, while the other dependent variables (reminiscence and decrement) were affected only by information, indicates the complexity of motor performance and the importance of measuring as many aspects of it as possible if the influence of independent variables is to be fully understood.

\section{REFERENCES}

AMMONS, R. B. Acquisition of motor skill: II. Rotary pursuit of performance with continuous practice before and after a single rest. Journal of Experimental Psychology, 1947, 37, 393-411.

CATALANO, J. F. Arousal as a factor in reminiscence. Perceptual \& Motor Skills, 1967, 24, 1171-1180.

CATALANO, J. F., \& WHALEN, P. M. Factors in recovery from performance decrement: Activation, inhibition, and warm-up. Perceptual \& Motor Skills, 1967a, 24, 1223-1231. 
CATALANO, J, F., \& WHALEN, P. M. The effects of auditory stimulation on pursuit rotor performance. Perceptual \& Motor Skills, $1967 \mathrm{~b}, 25,981-988$.

CROWNE, D, P., \& MARLOWE, D. A new scale of social desirability independent of psychopathology. Journal of Consulting Psychology, 1960, 24, 349-354.
EDWARDS, A. L. Edwards Personal Preference Schedule. New York: Psychological Corporation, 1954.

HULL, C. L. Principles of behavior. New York: Appleton-Century-Crofts, 1943.

STRICKLAND, B. R., \& JENKINS, O. Simple motor performance under positive and negative approval motivation. Perceptual \& Motor Skills, 1964, 19, 599-605.

\section{Intra-group similarity and the rejection of a deviate ${ }^{1}$}

JA Y HEWITT and DAVID MCLAUGHLIN, University of Victoria, Victoria, B.C., Canada

Each $S$ was informed that she was part of a five-person group, three of whose members agreed with her on a certain issue (the fellow members of the majority) and one of whom disagreed with her the deviate). In a 2 by 2 factorial design, Ss were lead to believe that they were either similar or dissimilar in personality to the other members of the majority and were either similar or dissimilar to the deviate. The Ss were given an opportunity to communicate with the deviate who refused to alter her initial position. The Ss broke off communication with the deviate sooner when there was a high similarity between themselves and the deviate than when there was a low similarity.

It seems logical to predict that the greater the similarity, attraction, or cohesiveness among the members of a group, the more time and effort will the group expend in attempting to modify the behavior of a deviate. Festinger's theory of informal social communication (Festinger, 1950) makes just the opposite prediction. Although high cohesive groups should initially expend greater effort in attempting to modify the behavior of a deviate, Festinger's theory predicts that if the deviate continues to violate the norms of the group, cohesiveness will be directly related to the speed with which the deviate will be rejected. The latter hypothesis has received some support when rejection is defined as a negative attitude toward the deviate. In experiments by Schachter (1951) and Emerson (1954), groups of Ss were asked to discuss a certain issue. A high degree of cohesiveness was induced in half of the groups, a low degree of cohesiveness in the remaining groups. A confederate (the deviate) was placed in each group and instructed to take a stand that was discrepant from the majority opinion. In both studies, the deviate was seen as a less desirable group member when group cohesiveness was high than when it was low.

The purpose of the present experiment was to extend the generality of these findings. In the Schachter (1951) and Emerson (1954) studies, rejection was defined as a negative attitude toward the deviate. In the present experiment, rejection was defined as the cessation of interaction with the deviate. In order to provide a more rigorous test of Festinger's hypothesis, however, several important aspects of the Schachter and Emerson procedure had to be modified. First, the Ss were allowed to communicate only with the deviate. In the Schachter (1951) and Emerson (1954) studies, Ss could communicate with anyone in the group. If Ss are allowed to communicate with anyone in the group, members of high cohesive groups might well direct fewer communications to the deviate during the final stages of communication than would their counterparts in low cohesive groups. This finding could be explained by assuming that the members of high cohesive groups had a greater desire to reject the deviate or by assuming that the members of high cohesive groups had a greater desire to communicate with one another. If Ss are allowed to communicate only with the deviate, the latter interpretation can be ruled out. The second major difference between the present study and the studies by Schachter (1951) and Emerson (1954) is that in the present study the relationship between the $S$ and the other members of the group was divided into two components. If the $S$ is a member of the majority, there can exist a high or low degree of similarity between himself and the other members of the majority and a high or low degree of similarity between himself and the deviate. Either dimension could be the critical variable to the exclusion of the other. However, since both dimensions make up the total degree of intragroup similarity, it was predicted that both dimensions would be directly related to the speed with which the $S$ would reject the deviate. The greater similarity between the $S$ and the other members of the majority and the greater the similarity between the $S$ and the deviate, the sooner should the $S$ break off communication with a nonconforming deviate.

\section{METHOD}

At a preliminary session, 32 females from an introductory sociology/ anthropology course at the University of Victoria were asked to fill out a personality questionnaire (the Leary Interpersonal Adjective Checklist). The Ss were then asked to participate in a subsequent experiment involving group discussion and were informed that the questionnaire would be employed in selecting the group members.

Upon arriving for the second session, the $S$ was seated in a small cubicle facing a one-way mirror, told to read a one-page description of a juvenile delinquent by the name of Johnny Rocco, and asked whether it would be better to send this person to prison or to a home for emotionally disturbed children. The $S$ was then asked to try to convince a "hypothetical other person" that the alternative she (the $S$ ) had picked was the best alternative. The $S$ talked over an intercom for $30 \mathrm{sec}$, rested for $30 \mathrm{sec}$, talked for $30 \mathrm{sec}$, etc., until she indicated that she had nothing further to say. The number of $30-\mathrm{sec}$ intervals employed by the $S$ was used to establish her operant rate.

The $S$ was then told that she was "Subject E" and (erroneously) that there were four other girls participating in the experiment: Ss A, B, C, and D. It was explained that each $S$ was located in a different room and that all rooms were connected via intercom. The $S$ was then given a card that indicated the relationship between her personality and the personalities of the other group members (information supposedly obtained from the personality questionnaire completed at the preliminary session). In one condition (high similarity to the majority, high similarity to the deviate), the card indicated that $S s \mathrm{~A}, \mathrm{~B}, \mathrm{C}, \mathrm{D}$, and $\mathrm{E}$ possessed a "Type I" personality and that no one possessed a "Type II" or "Type III" personality. In a second condition (high similarity to the majority, low similarity to the deviate), the card indicated that $S s A, B, C$, and $E$ possessed a "Type I" personality, that D possessed a "Type II" personality, and that no one possessed a "Type III" personality. In a third condition (low similarity to the majority, high similarity to the deviate), the card indicated that $S$ s $A, B$, and $C$ possessed a "Type I" personality, that D 